\title{
Mechanical Properties of Zircaloy-4 Cladding Tube by Advanced Expansion due to Compression (A-EDC) Test
}

\author{
Z. Zhao ${ }^{1, *}$, D. Kunii ${ }^{1}$, T. Abe ${ }^{1}$, H.L. Yang ${ }^{2}$, S. Kano ${ }^{2}$, Y. Matsukawa ${ }^{3}$, Y. Satoh ${ }^{3}$ and H. Abe ${ }^{2}$ \\ ${ }^{1}$ Graduate School of Engineering, Tohoku University, Sendai 980-8577, Japan \\ ${ }^{2}$ Department of Nuclear Engineering, School of Engineering, The University of Tokyo, Naka gun, Ibaraki 319-1188, Japan \\ ${ }^{3}$ Institute for Materials Research, Tohoku University, Sendai 980-8577, Japan
}

\begin{abstract}
A new testing technique named advanced expansion due to compression (A-EDC) has been developed with an attempt to study the hoop mechanical behavior of Zircaloy-4 cladding under the pellet-cladding mechanical interaction (PCMI) and the presumed reactivity-initiated accident (RIA). The Zircaloy-4 used in this work showed elongated grains in the tube longitudinal direction, large amounts of residual strain, and crystallographic texture. The finite element method (FEM) analysis illustrates that the A-EDC test shows a uniaxial tension in the hoop direction, which has also been confirmed by experiments. In addition, the hoop stress-strain curve has been derived at room temperature by the A-EDC tests. Moreover, the fractured surface has been observed in this research. [doi:10.2320/matertrans.ML201601]
\end{abstract}

(Received July 11, 2016; Accepted September 14, 2016; Published October 14, 2016)

Keywords: Zircaloy-4, pellet-cladding mechanical interaction (PCMI), advanced expansion due to compression (A-EDC), mechanical properties, hoop stress-strain curve

\section{Introduction}

Zirconium based alloys have widely used in nuclear power plants as key structural materials on account of their outstanding merits, such as low thermal neutron capture cross section, excellent corrosion behavior and acceptable mechanical properties. ${ }^{1,2)}$ If immerged into the aggressive coolant environment for a long time, cladding tubes are gradually degraded because of the corrosion reaction: $\mathrm{Zr}+2 \mathrm{H}_{2} \mathrm{O} \rightarrow$ $\mathrm{ZrO}_{2}+2 \mathrm{H}_{2}$, which results in the formation of oxide layer on the tube surface and hydrides in the tube interior. In some presumed accident scenarios, such as the early heat-up stage of RIA, PCMI will occur and may impose a level of stress on cladding materials. ${ }^{3)}$ Once the stress exceeded the mechanical property criteria, cladding tubes will fracture and leak radioactive materials.

Generally, the fuel cladding tubes have large enough size for mechanical tests in the longitudinal direction, for instance, the uniaxial tension tests. On the contrary, the size in the tube hoop direction is quite limited (merely $8-25 \mathrm{~mm}$ for outer diameter). It is necessary to design appropriate testing methods for investigating the stress-strain condition in the case of PCMI-induced failure. Until now, various of mechanical tests have been developed, including burst test ${ }^{4,5)}$ and ring compression $^{6,7)}$. Whereas these testing methods either have some shortages in appropriately simulating the PCMI in reactor, or some of them seem to be unable to achieve a definite stressstrain state. Among these mechanical test techniques, a conventional expansion due to compression (EDC) test was initially proposed with an object to measure the tangential expandability of beryllium tube. ${ }^{8)}$ Afterwards, the application of EDC test has been gradually adjusted and extended to the research field of nuclear fuel tubes, where axial compression of a polymer pellet inserted into tested cladding was conducted between a pair of pistons and the hoop expansion of inner pellet would lead to the failure of cladding. However, the con-

*Corresponding author, E-mail: zhaozishou@imr.tohoku.ac.jp ventional EDC is not well fit to accurately deduce the stressstrain relation up to severe deformation. There are difficulties in achieving reliable yield strength (YS) and ultimate tensile strength (UTS) due to the friction problems on the piston-pellet interface and piston-cladding interface. ${ }^{9)}$ On one hand, compression the pistons will make the Teflon inner pellet dense, so the friction between piston and pellet is variable, resulting in uncertain friction problem. On the other hand, in the condition of severe deformation, the clearance gap between pistons and specimen will cause leakage of inner pellet materials (Teflon), which also leads to the uncertainty of friction. Also, the size of the EDC test samples is too large for irradiation experiments, such as in materials testing reactors (MTRs). Moreover, at high temperature, since the softening and melting points of Teflon are $393 \mathrm{~K}$ and $600 \mathrm{~K}$, respectively, the EDC test is not applicable.

In order to obtain mechanical property in hoop direction and further study the PCMI experimentally, the new method named A-EDC test has been developed based on some modifications of the conventional EDC test. ${ }^{10)}$ In the modifications, the inner fillers were replaced by metallic pellets, and the cladding tube size was reduced to optimize the stressstrain state for PCMI. The reduction of specimen volume also offered the benefit that the future neutron and ions irradiation experiments became more feasible. Based on the above background, this paper is organized as follows. Firstly, the microstructure of Zircaloy-4 will be examined. Then, the stressstrain state will be analyzed by both the FEM and experiments. Through A-EDC tests, the mechanical property of Zircaloy-4, especially the hoop stress-strain relation, will be studied. Lastly, the fractured surface will be observed by scanning electron miscopy (SEM).

\section{Experimental Procedure}

Figure 1(a) shows the coordinate system of cladding tube composed of radial $(r)$, hoop $(\theta)$, and axial ( $z$ ) directions. Figure $1(\mathrm{~b})$ provides a schematic drawing of A-EDC test report- 

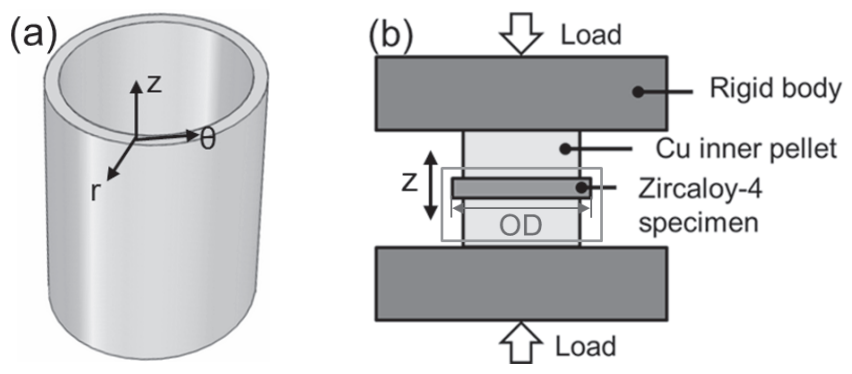

Fig. 1 (a) Coordinate system of the cladding tube; (b) schematic drawing of the A-EDC test. OD represents outer diameter of specimen.

ed in the previous research ${ }^{10)}$. In this configuration, commercially available pure $\mathrm{Cu}$ was set as an inner pellet (called IP), sandwiched between a pair of rigid bodies made of yttria-stabilized zirconia (YSZ). The initial diameter of $\mathrm{Cu}$ was $10 \mathrm{~mm}$, and then reduced to $8 \mathrm{~mm}$ by fine machining with a final height of $8 \mathrm{~mm}$. The Zircaloy-4 (Zr-1.3Sn-0.2Fe-0.1Cr) cladding was in a cold-worked and stress-relieved (CWSR) state. It had an inner diameter (ID) of $8.3 \mathrm{~mm}$ and an outer diameter (OD) of $9.5 \mathrm{~mm}$. The tube was cut into the ring-shaped specimen and grinded to $1 \mathrm{~mm}$ in width finally. A solid boron nitride lubricant was smeared on the surface of $\mathrm{Cu}$ to minimize the friction between $\mathrm{Cu}$ and specimen.

In the compression test at room temperature (RT), Shimadzu AG-100KNX plus was utilized, and both the height displacement and the diameter expansion of specimen were monitored and recorded by a laser measurer, Keyence TM3000. On one side, this device applied a set of parallel laser light to illuminates the $\mathrm{Cu}$ inner pellet, specimen and rigid bodies. On the other side, there was a CMOS image sensor to receive the laser light and form the projected image. On the image, one could set the regions of interest (or the measured region). The maximum length/outer diameter (OD) would be recorded every $50 \mathrm{~ms}$. Thus, the hoop strain has been defined by

$$
\varepsilon_{\theta \mathrm{i}}=\frac{\Delta \mathrm{OD}_{\mathrm{i}}}{\mathrm{OD}_{\mathrm{o}}}
$$

where $\varepsilon_{\theta \mathrm{i}}$ is the hoop strain at time $\mathrm{t}_{\mathrm{i}} ; \Delta \mathrm{OD}_{\mathrm{i}}$ means the increment of outer diameter at time $\mathrm{t}_{\mathrm{i}} ; \Delta \mathrm{OD}_{\mathrm{o}}$ represents the initial outer diameter (9.5 $\mathrm{mm}$ in this work).

The compression strain rate was $6.25 \times 10^{-4} \mathrm{~s}^{-1}$, which was equivalent to $2.0 \sim 4.5 \times 10^{-4} \mathrm{~s}^{-1}$ as the hoop strain rate of the specimen. The solo compression of $\mathrm{Cu}$ inner pellet was conducted. Meanwhile, another $\mathrm{Cu}$ inner pellet compression was carried out with specimen in the A-EDC test.

The microstructure of Zircaloy-4 was analyzed through electron backscatter diffraction (EBSD) technique. The sample for EBSD detection was electro-polished in a mixed solution of $10 \%$ perchloric acid, $20 \%$ butyl cellosolve, and $70 \%$ methanol (vol\%) at $-25^{\circ} \mathrm{C}$ and $10 \mathrm{~V}$. The scanning rate of electron beam was $0.2 \mu \mathrm{m} / \mathrm{s}$ during EBSD experiment. The fractured surface was observed by SEM.

\section{Experimental Results and Discussion}

\subsection{Microstructure of Zircaloy-4}

Figure 2 shows the inverse pole figure (IPF) and pole figure
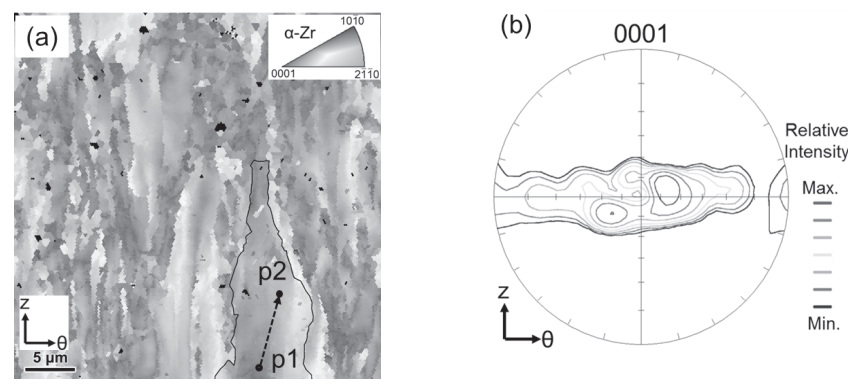

Fig. 2 Inverse pole figure (a) and pole figure (b) of as-recieved Zircaloy-4 A black curve was drawn in (a) denoting one of grains. See the text and Fig. 3 for "p1" and "p2".

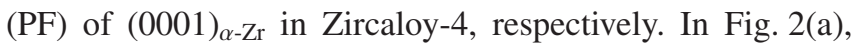
there are some color gradients inside an individual grain that indicate a large amount of residual strains as a result of stress relieved annealing. Besides, the grains are elongated in the tubular $z$ axis during manufacturing process as demonstrated by the elongated grain boundary (the black solid curve).

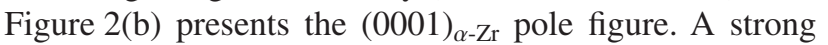
texture has been observed with the basal poles dominantly aligned in the radial direction with a split of $\pm\left(15^{\circ}-30^{\circ}\right)$ in the radial direction. This textured microstructure of cladding can be controlled by the $\mathrm{Q}$ factor ${ }^{1-13)}$, which equals to $\mathrm{R}_{\mathrm{w}} / \mathrm{R}_{\mathrm{D}}$, where $R_{W}$ represents the reduction of tube wall thickness and $R_{D}$ is the diameter reduction. In this research, $Q>1$ should be applied in the production process in view of the distribution

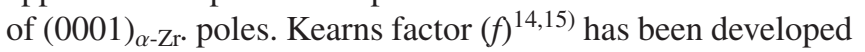
with an attempt to quantitatively describe the effective fractions of resolving $(0001)_{\alpha \text {-Zr }}$ poles distributed in each of the three tube principle directions: $r, z$, and $\theta$ directions. For the isotropic materials, their basal poles have equal distributions in three principle directions. However, the Kearns factors of Zircaloy-4 are $\sim 0.7$ in $r$ direction, $\sim 0.25$ in $\theta$ direction and $\sim 0.05$ in $z$ direction, respectively. Besides, this result was in a good accordance with the basal pole figure.

Figure 3 shows the misorientation evolution in an individual grain interior from $\mathrm{p} 1$ to $\mathrm{p} 2$ on the linear route as denoted by the dash line in Fig. 2(a). Since the Zircaloy-4 is in a CWSR state, even inside one grain, there is significantly large dislocation density. The dislocation contributes to the augment of divergences of crystal orientations, resulting in large misorientation degrees. In the investigation, the $\mathrm{p} 1$ was set to be the original point, and p2 was approximate $10 \mu \mathrm{m}$ away from it. Owing to the plastic deformations and accumulative strains, an obvious increment of $\sim 20$ misorientation degrees was found between $\mathrm{p} 1$ and p2. The insets in Fig. 3 also vividly illustrate the crystal orientations difference between the unit cells in p1 and p2, respectively. During the cold rolling, even the plastic deformation may seem to be homogeneous macroscopically, the inhomogeneous stain gradient can still exist between two grains and even inside a grain. ${ }^{16,17)}$

\subsection{Stress-strain relation}

\subsection{1 $\varepsilon_{z} / \varepsilon_{\theta}$ ratio and $\sigma_{z} / \sigma_{\theta}$ ratio in A-EDC test}

The FEM simulation of the A-EDC test has been conducted by H. Abe et al. ${ }^{10)}$ In the FEM simulation work, ANSYS workbench ver. 14.5 has been utilized for the $2 \mathrm{D}$ axial symmetry model. The mesh size for the specimen is $0.025 \mathrm{~mm}$, 
and for the $\mathrm{Cu}$ inner pellet, it is $0.05 \mathrm{~mm}$. The validity of the stress state was verified by simulation of the normal operation condition of the fuel using the FEMAXI-7 code ${ }^{18}$. In the ANSYS workbench simulation, the remote dispalcement boudary condition has been used to guide the vertical displacement of rigid body from $0 \mathrm{~mm}$ to $1.5 \mathrm{~mm}$, in order to compress the inner pellet. The contact type between rigid body and pellet was set to be rough. The contact type between pellet and specimen was frictional with the friction coefficient of 0.05 . For the rigid body-pellet and pellet-specimen contacted surfaces, the augmented Lagrange method has been applied as the contact formulartion.

Figure 4(a) depicts the geometry system of A-EDC FEM simulation. For simplification, three typical positions named ID, MD, and OD, have been picked out for further analysis. In Fig. 4(b) and (c), if the pellet-cladding friction coefficient is assumed to be 0.05 , the finite element method (FEM) analysis of the A-EDC test has revealed that the strain ratio of $\varepsilon_{z} /$ $\varepsilon_{\theta}$ fluctuates slightly around -0.5 , and the stress ratio of $\sigma_{z} /$

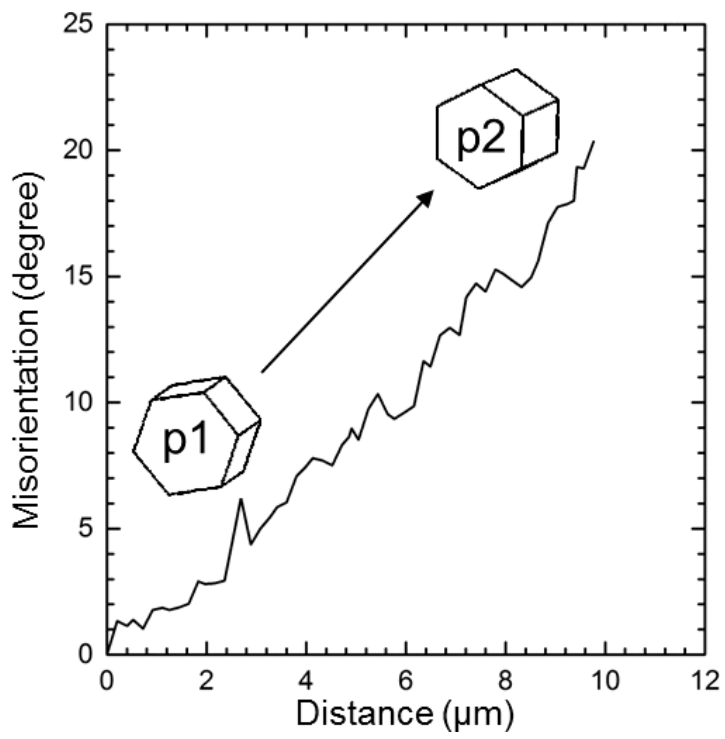

Fig. 3 Misorientation evolution from $\mathrm{p} 1$ to $\mathrm{p} 2$ inside one grain. $\mathrm{p} 1$ was set as original, and $\mathrm{p} 2$ was $\sim 10 \mu \mathrm{m}$ away from it. $\sigma_{\theta}$ remains nearly zero, which is close to the uniaxial tension requirments. ${ }^{9,10)}$ In the comparison, the FEM of conventional EDC test shows that its strain ratio is around -0.5 , but the stress ratio ranges from -0.25 to $0.2^{9,19)}$, which is probably ascribed to the variable friction on the pellet-cladding contact surface.

\subsubsection{Hoop stress-strain relation derived from A-EDC tests}

Figure 5 shows load-hoop strain and load-height displacement curves, where the hoop strain and height displacement belong to the cladding specimen and $\mathrm{Cu}$ inner pellet, respectively. In order to calculate the work consumed in specimen expansion, two separate tests should be performed. One is the solo $\mathrm{Cu}$ pellet compression, and the result has been indicated in the figure as IP. Another is carried out with a specimen around $\mathrm{Cu}$ inner pellet. The cross marks in the figure mean fracture of Zircaloy- 4 specimen. There is a drop appeared at $\sim 0.5 \mathrm{~mm}$ of height displacement in the load curve due to the removal of a jig manually when the plastic deformation of

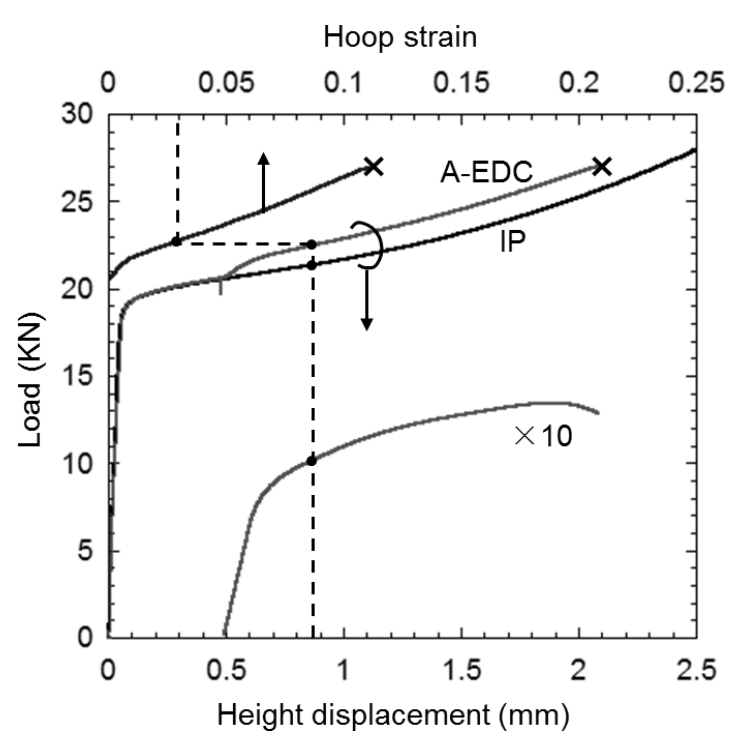

Fig. 5 Load-height displacement and load-hoop strain curves. IP-Cu inner pellet. (a)

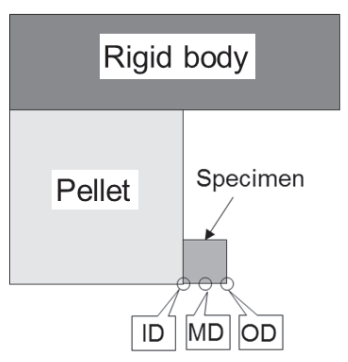

(b)

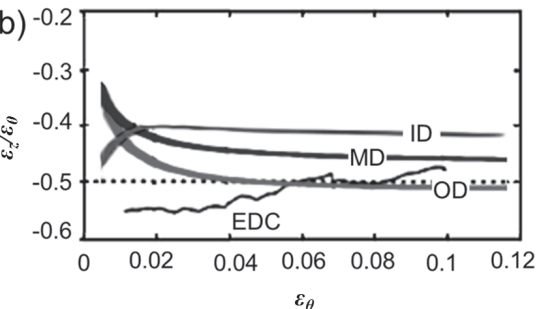

(c)

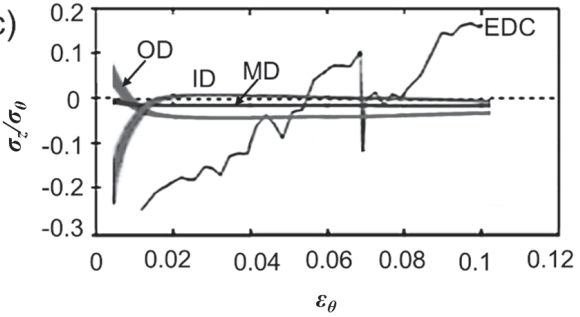

Fig. 4 (a) system of A-EDC simulation; Comparison of (b) $\varepsilon_{\mathrm{z}} / \varepsilon_{\theta}$ ratio and (c) $\sigma_{\mathrm{z}} / \sigma_{\theta}$ ratio in A-EDC and EDC ${ }^{9,19)}$ tests derived from FEM analysis; ID-Inner diameter; MD-Middle diameter; OD-Outer diameter. 
the inner pellet fairly fixed the position of the ring-shaped specimen. At the initial region (hoop strain $<3 \%$ ), the profiles of $\mathrm{Cu}$ inner pellets with and without specimen are not strongly affected by the specimen. This has been confirmed by the reference ${ }^{10)}$. The difference between load curves of IP and $\mathrm{A}-\mathrm{EDC}$, as shown in the bottom figure, is equivalent to the energy consumed by specimen expansion. In the severe deformation region, the main concerns in this work are the cladding tubes performance under PCMI such as the strain at fracture.

From the A-EDC experimental data, hoop stress-strain curves have been derived as shown in Fig. 6(a). Figure 6(b) shows the hoop strain vs time relation curve in tests 1 . In the test, the hoop strain did not keep a constant. At the early stage, the hoop strain rate was $\sim 2 \times 10^{-4} \mathrm{~s}^{-1}$. At the final stage before fracture, the hoop strain was approximately $4 \times 10^{-4} \mathrm{~s}^{-1}$.

Table 1 summaries the results of independent 4 tests of Zircaloy- 4 by A-EDC tests. The Young's modulus is 101 GPa; the $0.2 \%$ yield stress is $\sim 836 \mathrm{MPa}$; the ultimate yield stress is $\sim 1037 \mathrm{MPa}$; the maximum strain at fracture was $\sim 0.12$ on average. There are $3 \sim 5$ portions of necking observed in the specimens. Apparently, with the increment of necking portions, the maximum hoop strain exhibits a growth tendency in general. The strain ratio $\varepsilon_{z} / \varepsilon_{\theta}$ is about -0.41 , and the stress ratio $\sigma_{z} / \sigma_{\theta}$ is zero in A-EDC tests, which present good agreement with the FEM simulation in Fig. 4(b) and (c).

\subsection{Fractographic observations}

Figure 7 shows the observation of fractured surfaces in Zircaloy-4 after A-EDC tests. The overall view of fracture has been presented in Fig. 7(a). It exhibits a typical characteristic of about $45^{\circ}$ for ductile materials in the tube $z$ direction where shear stress reaches a maximum value. In Fig. 7(b), the fractured surface has been divided into three regions, named R1, R2 and R3. For R1 and R3, there are numerous fine dimples with a smeared feature which is supposed to be the reason of shear stress when necking occurs. ${ }^{20)}$ In addition, large quantities of fine dimples are distributed in the plateau region R2. Figure 7(c) shows the magnified view of one portion in R2, from which some tearing ridges and fine dimples are indicated by arrows. In the RIA case, the strain biaxiality ratio $\left(\varepsilon_{z}\right)$ $\left.\varepsilon_{\theta}\right)$ is close to 1 and the failure is triggered by through-thickness crack. M. Yamawaki's work ${ }^{21)}$ conducted research on the irradiated cladding tubes under the simulated RIA case. The results demonstrates that for the cladding tube failure, many incipient cracks vertically penetrate the brittle outer surface at the initial stage, and then one of them will propagate along nearly $45^{\circ}$ to the inner surface. Differently, the fracture of Zircaloy-4 in the A-EDC test exhibits that the crack plane propagates in the $z$ direction, which is probably caused by mutual influence of different stress-strain conditions and material microstructures (as received one and corroded-irradiated one).

\subsection{Discussion}

Table 2 summarized the mechanical properties of stress relieved Zircaloy-4 cladding tubes. All of these tests provide the mechanical properties in the tube hoop direction. It is evident that the A-EDC test has supplied more detailed mechanical properties than the others. Meanwhile, some slight disparities can still be observed. ${ }^{6,22-26)}$ Experimentally, the A-EDC test can achieve a stable uniaxial tension condition in the hoop direction throughout the test. For the other tests, some of them are unable to derive stress-strain relation by experiments. The only approach is using simulation methods in which the appropriateness of input parameters for simulation should be cautious because of the insufficient mechanical properties parameters in anisotropic Zircaloy-4 cladding tubes (e.g. the conventional EDC). Furthermore, some tests can only maintain a uniform stress-strain state at the early stage but fail later for stress gradient (e.g. the ring tension).

The anisotropic behavior of cladding is very common for zirconium based cladding tubes due to the combined effect of hexagonal closed packing (HCP) crystal structure and cold rolling process. In the A-EDC test, the plastic anisotropy of cladding tube has been investigated. The parameter, $\mathrm{R}$, is de-

Table 1 Mechanical properties of Zircaloy-4 derived from A-EDC tests.

\begin{tabular}{|c|c|c|c|c|c|c|c|}
\hline Tests & $\begin{array}{c}\text { Young's } \\
\text { Modulus } \\
{[\mathrm{GPa}]}\end{array}$ & $\begin{array}{c}0.2 \% \text { Yield } \\
\text { Stress } \\
{[\mathrm{MPa}]}\end{array}$ & $\begin{array}{c}\text { Ultimate } \\
\text { Strength } \\
{[\mathrm{MPa}]}\end{array}$ & $\begin{array}{l}\text { Strain at } \\
\text { Fracture }\end{array}$ & $\begin{array}{c}\text { Number of } \\
\text { Necking }\end{array}$ & $\varepsilon_{z} / \varepsilon_{\theta}$ & $\sigma_{z} / \sigma_{\theta}$ \\
\hline Test 1 & 108 & 878 & 1057 & 0.123 & 4 & & \\
\hline Test 2 & 104 & 843 & 1075 & 0.109 & 3 & & \\
\hline Test 3 & 97 & 861 & 1000 & 0.124 & 5 & -0.42 & 0 \\
\hline Test 4 & 95 & 760 & 1016 & 0.125 & 4 & & \\
\hline Average & 101 & 836 & 1037 & 0.120 & 4 & & \\
\hline
\end{tabular}
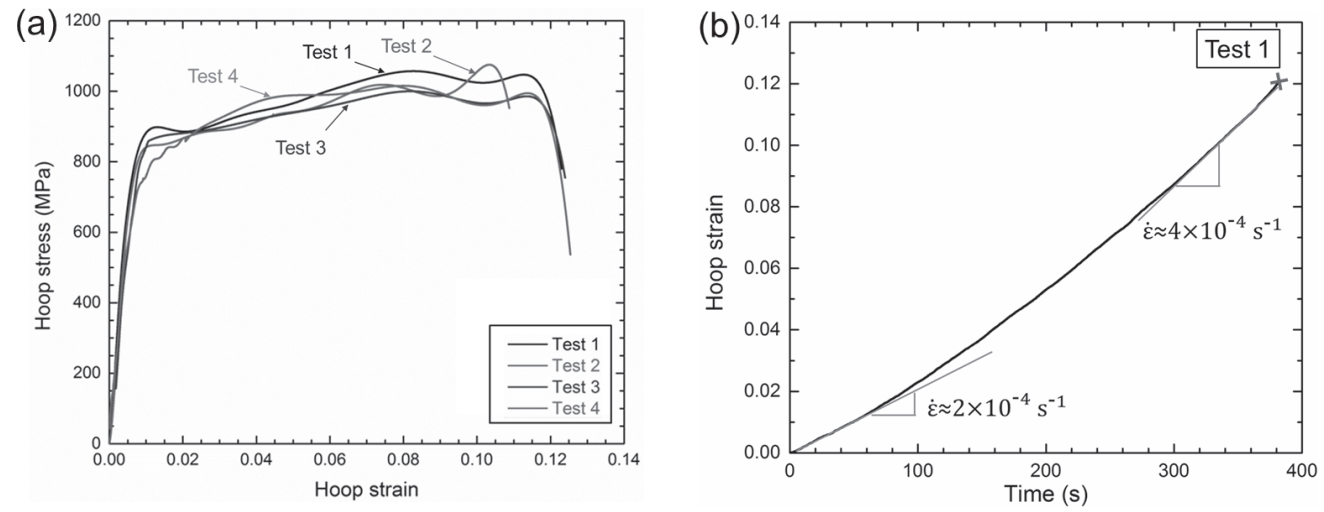

Fig. 6 (a) Hoop stress-hoop strain curves derived from A-EDC tests; (b) Hoop strain vs. time relation of test 1 in A-EDC tests. 


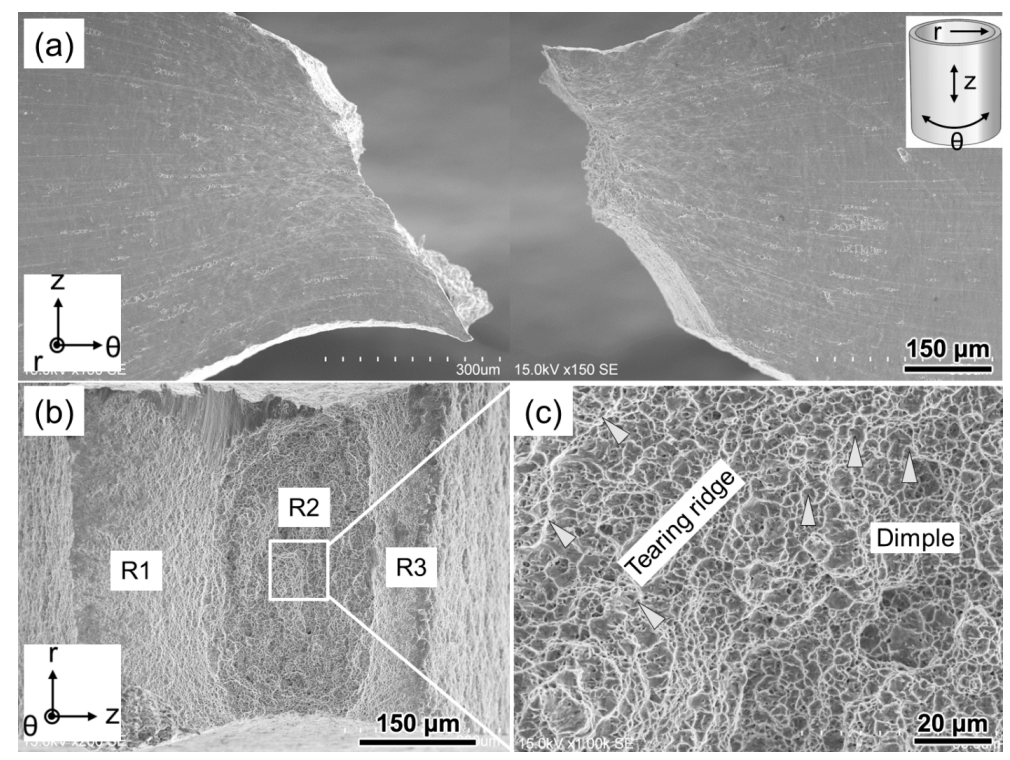

Fig. 7 SEM fractography of as-received Zircaloy4 after A-EDC tests.

Table 2 Comparisons of mechanical properties of Zircaloy- 4 in the tube hoop direction.

\begin{tabular}{|c|c|c|c|c|c|c|c|c|}
\hline Methods & $\begin{array}{c}\text { Young's Modulus } \\
{[\mathrm{GPa}]}\end{array}$ & $\begin{array}{c}0.2 \% \text { Yield Stress } \\
{[\mathrm{MPa}]}\end{array}$ & $\begin{array}{c}\text { Ultimate Strength } \\
{[\mathrm{MPa}]}\end{array}$ & Strain at Fracture & $\varepsilon_{z} / \varepsilon_{\theta}$ & $\sigma_{z} / \sigma_{\theta}$ & $\begin{array}{c}\text { Strain Rate } \\
{\left[\mathrm{s}^{-1}\right]}\end{array}$ & Ref. \\
\hline A-EDC & 101 & 836 & 1037 & 0.12 & -0.41 & 0 & $10^{-4}$ & This Work \\
\hline EDC & NA & 735 & NA & NA & -0.5 & $-0.2 \sim 0.2$ & NA & $9,19,22)$ \\
\hline R.T. (1) & NA & 718 & 718 & 0.35 & -0.5 & 0 & $10^{-2}$ & 26) \\
\hline R.T. (2) & NA & 830 & 950 & 0.50 & -0.7 & -0.5 & $10^{-2}$ & 24) \\
\hline PST & NA & 600 & 706 & 0.10 & 0 & 0.5 & $10^{-3}$ & 29) \\
\hline R.C. & 99 & 855 & 905 & 0.26 & 0 & 0.5 & NA & 6) \\
\hline Burst & NA & NA & 951 & 0.09 & NA & $0.5 \sim 1$ & NA & $26,32)$ \\
\hline
\end{tabular}

*All the data were obtained at room temperature; *R.T.-Ring tension; *PST-plane strain tension; *R.C.-Ring compression; *NA means that the data is not available

duced in the hoop direction, which is defined as follows ${ }^{13,27-29)}$ :

$$
R=\frac{\varepsilon_{z}}{\varepsilon_{r}}
$$

where $\varepsilon_{\mathrm{Z}}$ and $\varepsilon_{\mathrm{r}}$ are the width and thickness strains, respectively.

In this work, the value of $\mathrm{R}$ is about 1.6, which is larger than 1 , implying that wall-through slip is more difficult than the slip across cladding width. This can be identified by the necking along tube $z$ axis. In the previous studies, the parameter $\mathrm{R}$ values are found to be 1.3 tested in the axial direction $^{30)}$ and 2.3 tested in the hoop direction ${ }^{29)}$ for unirradiated Zircaloy-4. On the contrary, it has been proved that the yield condition of irradiated nuclear fuel cladding is similar to those of isotropic materials, which illustrates that irradiation can reduce the anisotropic behavior of cladding tubes. ${ }^{31)}$

\section{Conclusions}

The mechanical property of Zircaloy-4 in the hoop direction has been studied by the newly developed A-EDC tests. Based on the experimental data and fracture observation, the main conclusions in this research can be summarized as follows:

(1) The microstructure of Zircaloy-4 used in this work shows a strong anisotropic microstructure accompanied by a strong density of $(0001)_{\alpha \text {-Zr }}$ pole in the tube radial direction.

(2) The A-EDC test in this work can attain a uniaxial tension condition, where the $\varepsilon_{z} / \varepsilon_{\theta}$ ratio is close to -0.5 and the $\sigma_{z} / \sigma_{\theta}$ ratio is 0 . This has been verified through both the FEM analysis and experiments. Moreover, the A-EDC test is able to provide more information of mechanical properties than the other tests;

(3) The fracture behavior in A-EDC test is different from that in RIA case, which can be attributed to the combined effects of different stress strain states and material microstructures. The anisotropic mechanical behavior of stress relieved Zircaloy-4 has been confirmed in the A-EDC tests.

\section{Acknowledgements}

This work is supported by the project of "R\&D of nuclear fuel cladding materials and their environmental degradations 
for the development of safety standards" entrusted to Tohoku University by Ministry of Education, Culture, Sport, Science and Technology of Japan (MEXT), and "Study on hydrogenation and radiation effects in advanced nuclear fuel cladding materials" conducted under the Strategic Promotion Program for Basic Nuclear Research by MEXT.

\section{REFERENCES}

1) C. Coleman: Zirconium in the Nuclear Industry, 5th International Smposium, ed. by (ASTM STP 754-EB, 1982) pp. 393-411.

2) K.B. Colas, A.T. Motta, J.D. Almer, M.R. Daymond, M. Kerr, A.D. Banchik, P. Vizcaino and J.R. Santisteban: Acta Mater. 58 (2010) 65756583.

3) L.O.M. Jernkvist, Ali R: Nuclear Fuel Behaviour under Reactivity-initiated Accident (RIA) Condition: State-of-the-art Repor, (Nuclear Energy Agency, Organisation for Economic Co-operation and Development (OECD), Place, 2010) pp. 51-53.

4) A. Hermann, S.K. Yagnik and D. Gavillet: J. ASTM Int. 4 (2007) 1-20.

5) A.M. Garde, G.P. Smith and R.C. Pirek: 11th International Symposium on Zr in the Nuclear Industry, ed. by (ASTM STP 1295, 1996) pp. 407430.

6) V. Busser, M.-C. Baietto-Dubourg, J. Desquines, C. Duriez and J.-P. Mardon: J. Nucl. Mater. 384 (2009) 87-95.

7) F. Nagase, T. Sugiyama and T. Fuketa: J. Nucl. Sci. Technol. 46 (2009) $545-552$.

8) Y. Mishima: J. Nucl. Sci. Technol. 3 (1966) 294-297.

9) J. Desquines, D.A. Koss, A.T. Motta, B. Cazalis and M. Petit: J. Nucl. Mater. 412 (2011) 250-267.

10) H. Abe, T. Abe, S. Kishita, S. Kano, Y. Li, H. Yang, K. Tawara, Y. Matsukawa and Y. Satoh: J. Nucl. Sci. Technol. 52 (2015) 1232-1239.

11) E. Tenckhoff: Zirconium in the Nuclear Industry, 5th International Smposium, ed. by (ASTM International, 1982) pp. 5-21.

12) H. Abe, H. Tarui, T. Kobayashi, M. Honji and T. Konishi: Zirconium in the Nuclear Industry: Ninth International Symposium, ed. by C.M. Eucken, (ASTM International, 1991) pp. 35-47.

13) K. Linga Murty and I. Charit: Prog. Nucl. Energy 48 (2006) 325-359.

14) J. Kearns: WAPD-TM-472, (Bettis Atomic Power Lab., Pittsburgh, PA (USA), 1965).

15) J. Kearns: J. Nucl. Mater. 299 (2001) 171-174.

16) S. Sun, B.L. Adams and W.E. King: Philos. Mag. A 80 (2000) 9-25.

17) A.J. Schwartz, W.E. King, G.H. Campbell, J.S. Stölken, D.H. Lassila, S. Sun and B.L. Adams: J. Eng. Mater. Tech. 121 (1999) 178-181.

18) M. Suzuki, H. Saitou and Y. Udagawa: JAEA-Data/Code 35 (2010) 2010.

19) O. Dufourneaud, A. Varias, V. Grigoriev, R. Jakobsson and D. Schrire: JAERI-Conference, (JAERI, Japan, 2002) pp. 142-162.

20) B.V. Cockeram and K.S. Chan: J. Nucl. Mater. 434 (2013) 97-123.

21) M. Yamawaki, K. Yamaguchi, T. Fuketa, H. Sasajima, Y. Mori and K. Ishijima: J. Nucl. Mater. 248 (1997) 249-256.

22) T. Fukuda, T. Mihara, M. Amaya, T. Sugiyama and F. Nagase: International Atomic Energy Agency (IAEA) (2013) 77-83.

23) S.-K. Kim: Advances in Nuclear Fuel, ed. by (InTech, 2012) pp. 143158.

24) R.S. Daum: Hydride-induced Embrittlement of Zircaloy-4 Cladding under Plane-strain Tension, Doctoral thesis, Penn State University, (2007) pp. 105-115.

25) A. Hellouin de Menibus, Q. Auzoux, P. Mongabure, V. Macdonald, T. Le Jolu, J. Besson and J. Crepin: Mater. Sci. Eng. A 604 (2014) 57-66.

26) J.H. Kim, M.H. Lee, B.K. Choi and Y.H. Jeong: J. Alloy. Compd. 431 (2007) 155-161.

27) S.R. Agnew and Ö. Duygulu: Int. J. Plast. 21 (2005) 1161-1193.

28) R.W.L. Fong: J. Nucl. Mater. 440 (2013) 288-297.

29) T.M. Link, D.A. Koss and A.T. Motta: Nucl. Eng. Des. 186 (1998) 379-394.

30) P. Delobelle, P. Robinet, P. Bouffioux, P. Geyer and I. Le Pichon: Zirconium in the Nuclear Industry: Eleventh International Symposium, ed. by (ASTM STP 1295, 1996) pp. 373-321.

31) M. Nakatsuka: J. Nucl. Sci. Technol. 28 (1991) 356-368.

32) H.M. Chung and T.F. Kassner: Nucl. Eng. Des. 186 (1998) 411-427. 